\title{
Lack of relationship between right ventricular volume, degree of pulmonic regugitation (PR) and left ventricular function in repaired Tetralogy of Fallot (TOF) Tsun-Hou Chang*1 and Harold Litt ${ }^{2}$
}

Address: ${ }^{1}$ Tri-Service General Hospital, Taipei, Taiwan and ${ }^{2}$ University of Pennsylvania School of Medicine, Philadelphia, PA, USA

* Corresponding author

from 13th Annual SCMR Scientific Sessions

Phoenix, AZ, USA. $21-24$ January 2010

Published: 21 January 2010

Journal of Cardiovascular Magnetic Resonance 20 10, I2(Suppl I):P22 doi:I0.1 I86/I532-429X-I2-SI-P22

This abstract is available from: http://jcmr-online.com/content/I2/SI/P22

(C) 2010 Chang and Litt; licensee BioMed Central Ltd.

\section{Introduction}

Previous studies of small numbers of patients have shown conflicting results concerning the effect of RV dilation and PR on LV function, with some showing an inverse correlation between LV EF and RV volume and pulmonic regurgitant fraction, and others demonstrating no effect.

\section{Purpose}

To evaluate the correlation between LV EF and RV volume and degree of PR in a larger group of patients with repaired TOF.

\section{Methods}

103 consecutive MRI exams performed on adults with repaired TOF from 2005-2009 were reviewed; 11 studies obtained after pulmonic valve replacement were excluded, leaving 92 exams in 78 patients for analysis. RV end-diastolic volume (indexed to body surface area) and LV EF, obtained from SSFP cine images, and pulmonic regurgitant fraction, obtained from velocity encoded phase contrast images, were recorded.

\section{Results}

Mean indexed RV EDV was $149 \mathrm{ml} / \mathrm{m}^{\wedge} 2$ (range 67-404), mean pulmonic regurgitant fraction was $27 \%$ (range 0 66 ) and mean LV EF was 56\% (range 32-73). There was no significant correlation between either RV EDV or PR and LV ejection fraction, ( $\mathrm{r} 2=0.005$ and 0.03 , respectively) (Figures 1, 2 and 3). There was a moderate correlation between RV EDV and degree of PR, r2 = 0.2 ( 0.29 if outlying RV sizes are excluded).

\section{Conclusion}

No significant relationship was detected between LV ejection fraction and RV size or degree or PR in a large, heterogeneous group of adults with repaired TOF. LV function remains well preserved in many patients with very large RV volume and severe PR. Diminished LV function can occur with any level of RV dilation or pulmonic regurgitation, and appears to be related to factors other than RV volume overload.

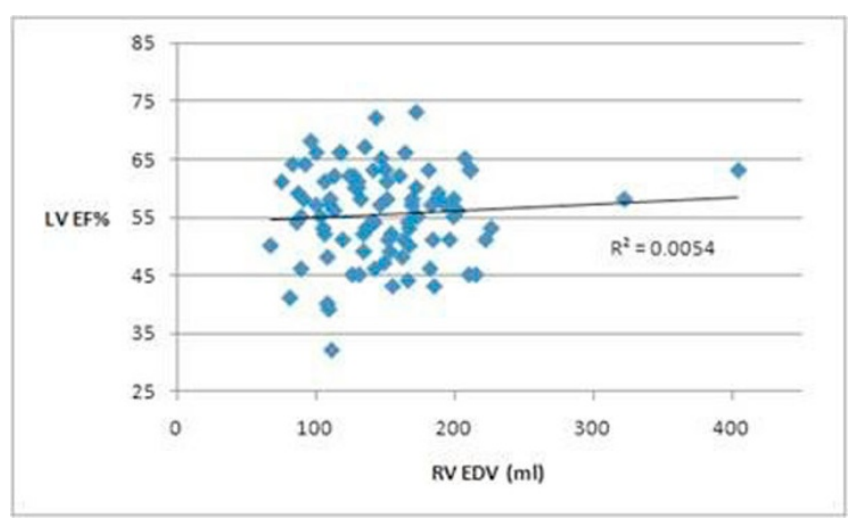

Figure I 


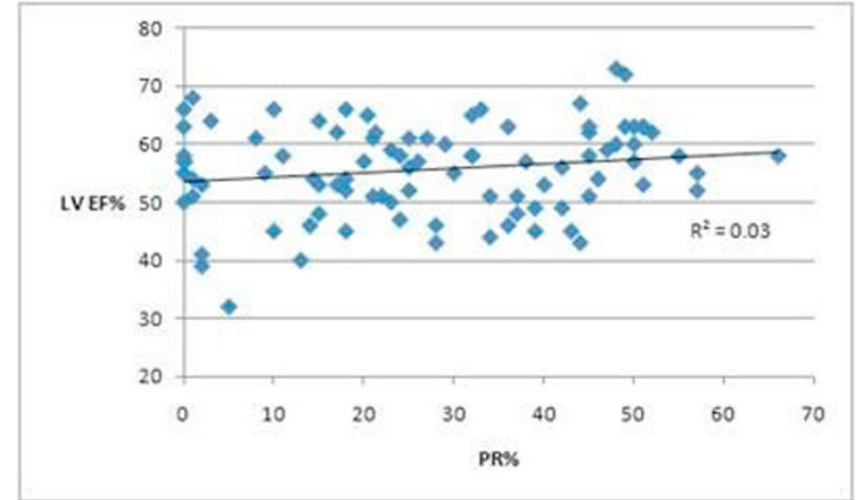

Figure 2

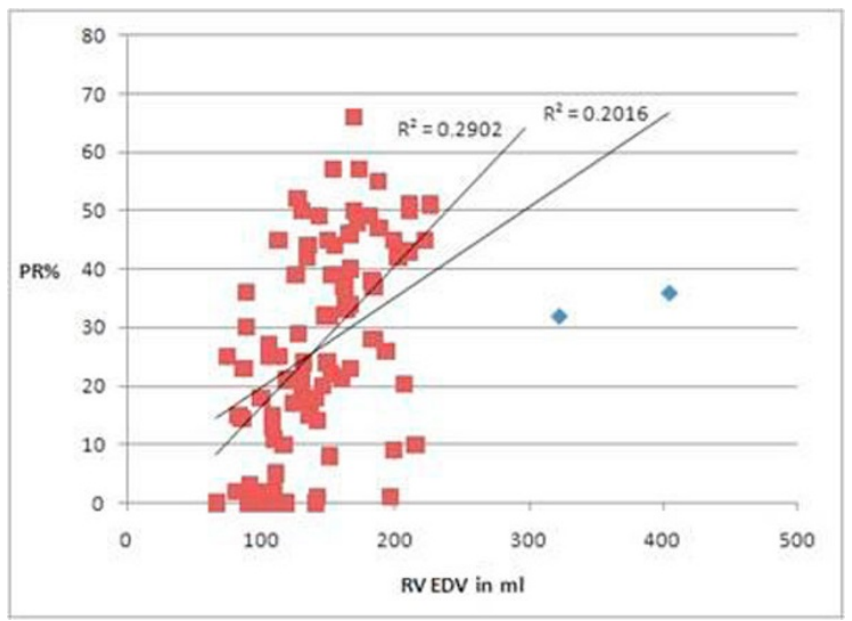

Figure 3
Publish with Biomed Central and every scientist can read your work free of charge

"BioMed Central will be the most significant development for disseminating the results of biomedical research in our lifetime. " Sir Paul Nurse, Cancer Research UK

Your research papers will be:

- available free of charge to the entire biomedical community

- peer reviewed and published immediately upon acceptance

- cited in PubMed and archived on PubMed Central

- yours - you keep the copyright

Submit your manuscript here:

http://www.biomedcentral.com/info/publishing_adv.asp

Page 2 of 2 